\title{
Chapter 5 \\ The Relationship between Online and Offline Play: Friendship and Exclusion
}

\author{
Jackie Marsh
}

In this chapter, the relationship between children's play in online and offline environments is explored. For children in contemporary societies, the boundaries between these two domains are becoming increasingly blurred as children's play spaces expand to include online sites. In the project outlined in this book, we were interested in the way in which children's play has changed in recent decades, especially with the influence of media and new technologies. Given that children are spending increasing amounts of time online, it is inevitable that their play activities now move across virtual and non-virtual domains. The chapter identifies both the continuities and discontinuities in this play, focusing on children in Monteney Primary School in Sheffield. The extent and nature of children's engagement in online activities is outlined and the way in which friendships are constructed across online and offline spaces is analysed. The chapter concludes with a consideration of the implications of this analysis for the study of play.

\section{Children's Online Activities}

Online activities are now prevalent in many children's lives (Livingstone, 2009). Ofcom $^{1}$ (2011) report that 91 per cent of children aged 5 to 15 in the UK have access to the Internet at home. Children are engaged in online activities in their earliest years of life, often supported by their families as they access Internet games and communicate with family members (Blanchard and Moore, 2010; Marsh et al, 2005). These practices create alarm for some who suggest, despite an absence of convincing empirical data in this area, that young children should not be encouraged to engage with such technologies as they can be detrimental to development (Levin and Rosenquest, 2001; Palmer, 2006). But many families encourage and celebrate their young children's emergence into the digital age. For example, babies engage in Skype conversations conducted by their families, toddlers navigate complex online screens and take immense pleasure in their interactions with iPads and iPhones and some of this activity is video recorded by proud parents and placed

1 OFCOM (Office for Communications) is the UK media regulator. 


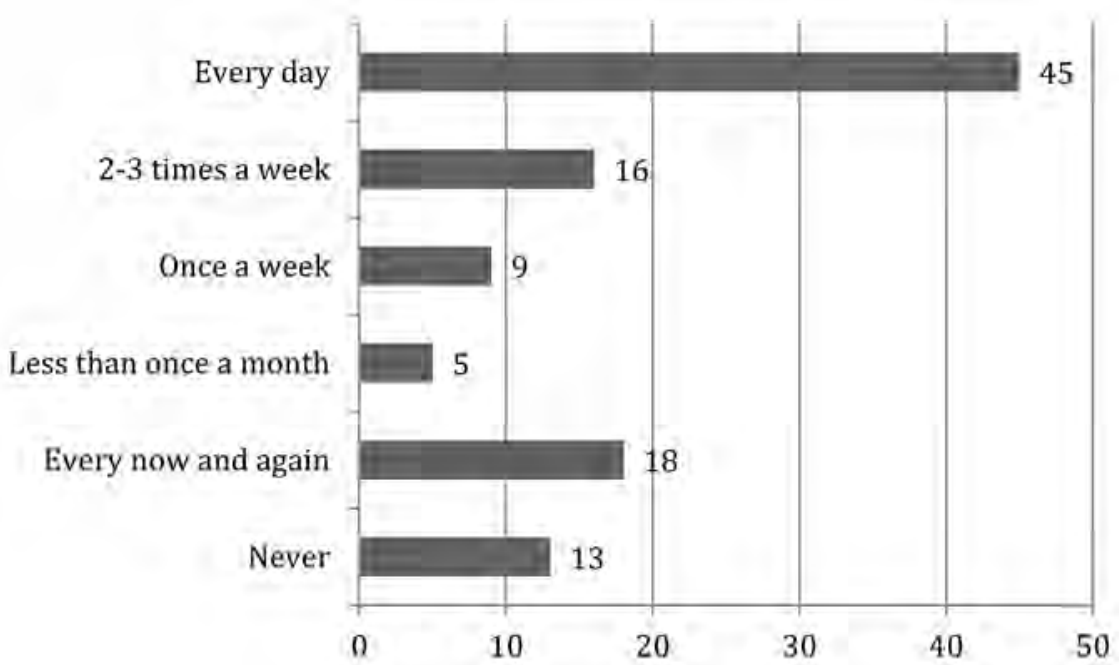

Fig. 5.1 Per cent frequency of Internet use $(\mathrm{n}=173)$

on YouTube ${ }^{2}$ as a testament to their 'toddler netizens' (Luke, 2000). Given the extensive engagement that many children have in family digital literacy practices in their earliest years it is inevitable that by the time children attend primary school, many of them are already competent users of the Internet.

This was the case with the children in the present study. At Monteney Primary School, 180 children aged 5-11 completed a survey of their media-related activities. One hundred and seventy three children completed a question which asked them to report on the frequency with which they accessed the Internet. Figure 5.1 outlines the responses.

Given that 70 per cent of children reported using the Internet at least once a week or more frequently, it is of no surprise that the range of Internet activities in which they engaged was wide and included the use of websites related to media brands (e.g. Disney) and favourite television channels and programmes, virtual worlds, Massively Multiplayer Online Games (MMOGs), games and social networking sites. Children were asked to list their favourite websites and the sites listed are outlined in Table 5.1.

2 See, for example: Skype: http://www.youtube.com/watch?v=HIr0O-IAoxQ; Internet site: $h$ ttp://www.youtube.com/watch? $\mathrm{v}=\mathrm{aYUYpzN}-\mathrm{P} 8 \mathrm{~g} ;$ iPad: http://www.youtube. $\mathrm{com} /$ watch? $\mathrm{v}=$ MGMsT4qNA-c; iPhone: $h$ ttp://www.youtube.com/watch? $\mathrm{v}=\mathrm{oZwKPDv} Y A$ $2 \mathrm{M} \&$ feature $=\mathrm{fvsr}$.

\section{(c) Copyrighted Material}

Copyright material: You are not permitted to transmit this file in any format or media; it may not be resold or reused without prior agreement with Ashgate Publishing and may not be placed on any publicly accessible or commercial servers. 
Table 5.1 Children's favourite Internet sites

\begin{tabular}{|c|c|}
\hline Type of site & Sites named \\
\hline Browsers & Google; Firefox; Internet Explorer \\
\hline Social networking sites & Facebook; Bebo; MySpace \\
\hline Virtual worlds & Club Penguin; Moshi Monsters; Farmville \\
\hline $\begin{array}{l}\text { Massive Multiplayer Online } \\
\text { Games (MMOGs) }\end{array}$ & Age of War 2; Runescape; Sacred Seasons; Evony \\
\hline $\begin{array}{l}\text { Sites related to favourite } \\
\text { brands/toys/films/TV } \\
\text { programmes/videogames }\end{array}$ & $\begin{array}{l}\text { Barbie; Mario Bros; Gogo's Crazy Bones; Hannah } \\
\text { Montana; Doctor Who; Simpsons; Mister Maker }\end{array}$ \\
\hline $\begin{array}{l}\text { Sites related to television } \\
\text { channels }\end{array}$ & $\begin{array}{l}\text { 'Watching TV on the Internet'; CBBC; CBeebies; } \\
\text { Cartoon Network; Disney }\end{array}$ \\
\hline Video sites & YouTube \\
\hline Shopping sites & eBay \\
\hline Music sites & Limewire; Grooveshark; Monstrosity \\
\hline Email/chat sites & MsN; Hotmail; Google Mail \\
\hline Creative/arts sites & Pizco; Capzles; Tux Paint \\
\hline Education sites & Smart Kiddy; Studywiz; Education City \\
\hline Various games sites & $\begin{array}{l}\text { 'Free online games'; mostfungames.com; bored. } \\
\text { com; stickpage.com; Miniclip; crush the castle, } \\
\text { motorbike games, car/parking games, racing } \\
\text { games, drifting games, animal games, girls go } \\
\text { games; Roblox; Playfg; Orsinal; Friv; Poker games; } \\
\text { Games for girls; Dressing up games (e.g. Stardolls); } \\
\text { Game station; Cartoon games; E zone; Flonga }\end{array}$ \\
\hline
\end{tabular}

It can be seen from Table 5.1 that many of these sites were not aimed primarily at children aged 11 and under (such as Facebook, which has a registration age of 13), but younger children have always accessed media texts that are considered more appropriate for teenagers and adults (Buckingham, 1993). For the children at Monteney, online activities were embedded in their everyday lives and it is, therefore, inevitable that traces of these activities can be discerned in the children's playground culture. As Rebekah Willett's chapter reporting the parallel study at Christopher Hatton indicates, numerous episodes of play related to some of the texts above were observed or reported in this study, such as Disney texts, Super Mario and Doctor Who. These have been embedded in children's cultural worlds for many years and, indeed, the studies conducted by Iona and Peter Opie documented the way in which children drew on pop music, television and films in their play (Opie and Opie, 1988). A relatively new phenomenon, however, is children's developing interest in online virtual worlds, a number of which appeared as children's favourite Internet sites in Table 5.1. In the next sections, I move on to consider the prevalence of these sites in children's cultural practices and outline their use by children in this primary school in order to explore the offline-online continuum. 


\section{Virtual Worlds for Children}

Children's toys and cultures reflect the zeitgeist of a given era (Warner, 2009). It is no surprise, therefore, that there has been an increase in the development of virtual worlds for children, given the general interest in these sites. Online virtual worlds are immersive 2D or 3D simulations of persistent space in which users adopt an avatar in order to represent themselves and interact with others. They may or may not include game elements. The burgeoning of the children's virtual world market began around the mid-point of the first decade of the twenty-first century, with some of the current major players, such as Ganz's Webkinz and Viacom's Neopet beginning to attract large numbers of users around that time. Since then, this has been an area of rapid development, with some reports that the fastest growing demographic of virtual world users is children between the ages of five and nine. It has been reported that there are now over 150 virtual worlds either operating or in development that are aimed at children and young people under 18 years of age, with approximately 355 million users aged five to 10 of virtual worlds. ${ }^{3}$

The majority of children's virtual worlds involve playing games as a major activity. This is not to suggest, however, that the worlds should be categorized primarily as games. As Meyers (2009) argues, the activities undertaken in what he terms 'shared virtual environments' (SVEs) have more in common with virtual worlds for adults, such as Second Life, than other online game sites. Many of the sites enable users to manage an avatar (clothe and manipulate an online representation of themselves) create home environments, chat to others through the use of instant messaging and engage in shopping for virtual artefacts. These virtual worlds promote a range of types of play from the more restricted rulebound play involved in games constructed by the site producers to imaginative play, which can involve fantasy and socio-dramatic play (Marsh, 2010).

In order to avoid the difficulties faced in any simplistic dichotomization of the 'real' and 'virtual' (see Marsh, 2010, for further discussion of this binary), in this chapter I use the terms 'offline' and 'online' to distinguish between those periods when children use online virtual worlds and those periods when they are not engaged in the use of the Internet or computer in their play.

\section{Children's Use of Virtual Worlds}

In the survey of media use completed by children in Monteney Primary School, 168 children responded to the question asking whether or not they used virtual worlds. Ninety per cent stated that they did so and the virtual worlds they reported using included Club Penguin, Moshi Monsters, Bin Weevils, BarbieGirls, Webkinz, Habbo Hotel and the MMOGs Runescape and World of Warcraft. This was in contrast to a survey conducted at the same school two years previously, in which 52 per cent of 175 children surveyed stated that they used virtual worlds (Marsh,

$3 \quad$ KZero, http://www.kzero.co.uk/universe.php.

\section{(C) Copyrighted Material}

Copyright material: You are not permitted to transmit this file in any format or media; it may not be resold or reused without prior agreement with Ashgate Publishing and may not be placed on any publicly accessible or commercial servers. 
2010; 2011), supporting the arguments made by Gilbert (2009) about the growth in the use of these worlds over time. Children at Monteney were thus familiar with the concepts of virtual worlds and avatars at an early stage of their commercial development, and this may be in part because the ICT teacher, Peter Winter, had undertaken activities in his classes in which children developed avatars in the form of 'Weemees'.

Children were asked which websites they discussed with their friends. Responses included: Runescape, Moshi Monsters, Bin Weevils, Club Penguin and World of Warcraft. One child described Moshi Monsters:

moshi monster it is a pet you look afther and you can chat to your frinds at home and you have to feed you moshi monster and play daily games on it so yoju can get monmey to feed it with and by it stof.

For younger children, playing games offers a strong attraction for engaging with virtual worlds. The UK Children Go Online Survey identified that 70 per cent of nine to 19 year-olds in the UK played games on the Internet at least weekly (Livingstone, 2009: 45) which indicates the attraction of online games for tweens and teenagers and their younger counterparts are no exception. As the survey quote above indicates, these sites frequently enable users to adopt and look after pets which need constant attention, otherwise users receive reminders about the need to look after them or even, as in the case of Club Penguin, are informed that their neglected pets have run away. These requirements are very much related to the producers' desire to promote 'stickiness', that is, to ensure children keep returning to the sites over time.

This child's comment about getting money to feed a pet on Moshi Monsters also indicates the way in which commercialised practices are embedded in these sites. Users earn in-world currency through the completion of games, currency which they then use to buy virtual items for their avatars, pets and virtual homes. Embedded within the moral panic discourses surrounding children's use of technology, the child is frequently constructed as the "subject of consumption" the individual who is imagined and acted upon by the imperative to consume' (Miller and Rose, 1997:1). Children are, most certainly, embedded in commercial play worlds that drive consumption of economic goods from an early age.

Cook (2010), however, argues that we need to move beyond the traditional discussions of children's socialisation into commercial activity, as these discussions frequently do not acknowledge the complexity of children's engagement in consumer culture. Instead, he posits the concept of 'commercial enculturation' as a means of signifying that participation in commercial activities does not follow a linear trajectory in relation to age, but rather children's consumption is culturally defined and shaped through social relationships. Further, Pugh (2009) suggests that the kind of social practices in which children develop peer networks through shared economic interests, such as collecting and swapping consumer items linked to popular cultural interests (at Monteney, for example, children collected Club Penguin cards), should be seen as 'an economy of dignity'. She argues that 
children 'collect or confer dignity among themselves according to their (shifting) consensus about what sort of objects or experiences are supposed to count for it' (Pugh, 2009: 6-7). The key motivation for engaging in these collective expressions of consumerism is to seek a sense of belonging. This is not to suggest, however, that we need to be unconcerned about the way in which children are positioned as consumers. As Buckingham (2011) contends, there is a need to explore the complexities embedded within the relationship between childhood and the commercial world in order to identify the ways in which children are positioned within markets and to develop strategies for facilitating their critical engagement with this positioning. In this way, a reductive and narrow rejectionist agenda is avoided and children's own agency in navigating these waters will be enhanced.

A further question on the survey asked children to say something about mediarelated games they played in the playground. Two children mentioned games which included an avatar:

its called mythical people and I am a made up greture called an avater who can do anything and my best friend aiden is a wizard

it is called mythical people i am a wizard and angela is an avatar how can do eneything

In these two examples, the children grafted aspects of virtual worlds (i.e. avatars) onto sedimented play practices related to wizards and mythical creatures, staple characters in children's play over time. As Burn suggests in Chapter 1, this can be characterised as cultural rehearsal, a process in which the old and new are remixed in a single practice. We can also see it as an example of heterotopian games, in which cultural resources for game-making are imported into the playground from the online world.

There is a growing relationship between children's online and offline play. Lauwaert (2009) suggests that the 'geography of play' now consists of physical and digital artefacts and practices, both core and peripheral, many of which are connected to each other. This is very much the case in relation to recent developments of virtual worlds, in which 'clickable' technologies are used to create artefacts that can store information from the virtual play and be transferred to other players. For example, Disney has in recent years launched a virtual world titled Pixie Hollow. Children are able to purchase bracelets that can be used to exchange game credits with other players. Many virtual worlds for children are linked to key brands (e.g. Barbie, Lego) and therefore the spatial boundaries of play are becoming blurred as children move across online and offline worlds. At Monteney School, children reported owning a range of toys and artefacts related to their use of virtual worlds, such as Club Penguin collecting cards and puffles. Club Penguin is also available on different platforms, such as Nintendo DS, and children reported playing across these platforms. Games related to Club Penguin were played on the playground and thus the circulation of the Club Penguin narrative and associated discourses occurred across a range of online and offline spaces. Whilst it is becoming 
increasingly clear that there is a continuum between online and offline play, this does not mean that there are no palpable distinctions between them. As Boellstorff (2008) suggests, engaging in online activity is qualitatively different from offline activity. There are obvious modality differences. Manipulating an avatar is not the same as navigating one's physical body through space. Nevertheless, there are overlaps between online and offline identities. Malpas notes that:

A basic starting point for any serious discussion of the virtual must be recognition of the non-autonomy of the virtual - a recognition of the fact that the virtual does not constitute an autonomous, independent, or 'closed' system, but is instead always dependent, in a variety of ways, on the everyday world within which it is embedded. (Malpas 2009:135).

Online and offline identities inter-relate (Robinson, 2007), although there is evidence that suggests that Internet users do play and experiment with their online identities, developing aspects of their identity which they would not perform in an offline context (Boellstorf, 2008; Nardi, 2010; Kafai, Fields and Cook, 2010).

Given the extent to which children played online in virtual worlds, I was interested in the impact this had on their friendships. How far did children play with other children online that they played with in the playground at school? Did children who were not engaged in extensive online play feel more excluded from playground activities? In order to explore these questions, I asked children to create sociograms and then interviewed a group of children about peers they played with online and offline, drawing on the diagrams they had created. Sociograms are, according to Rapoport and Horvath (1961: 279), 'a description of the population in terms of relationships between pairs of people in that population'. In this method, research participants indicate their connections to other people in a specific group, relationships that are then mapped through network diagrams. In the following section, I outline the process of collecting these data before moving on to examine the themes that emerged from the analysis.

\section{Online and Offline Friendships}

Children in 11 of the 12 Year One to Six classes across the school were given a list that contained the names of all the children in their class inside individual circles. They were then asked to draw a black line to a circle that contained the name of a friend they played with in the playground and a red line to a circle that contained the name of a friend that they played with online, in the range of sites outlined in Table 5.1. One hundred and forty-five children completed the diagrams. The data were then analysed at a whole class level for six classes, as not all children in the other five classes completed the diagrams. An example of a sociograph of online and offline friendships developed from the data from children in one class can be found in Figures 5.2 and 5.3. 


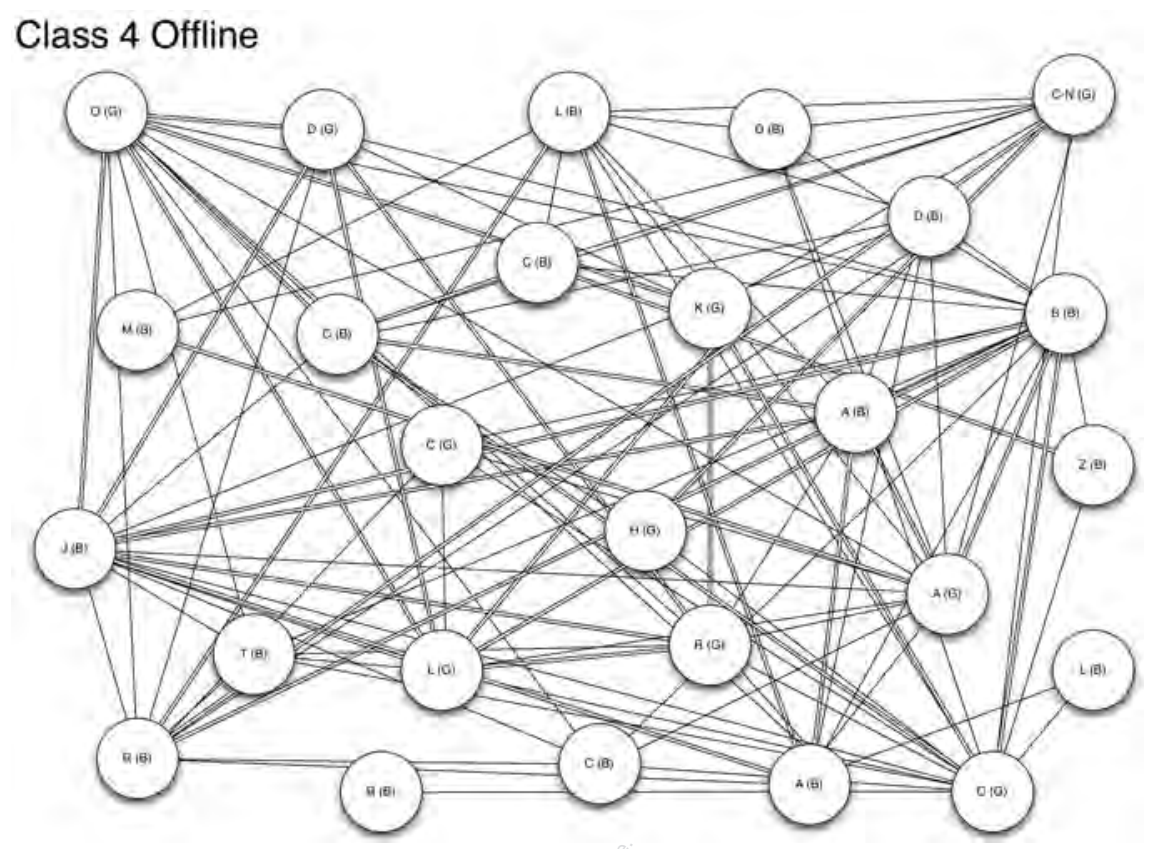

Fig. 5.2 Offline friendships in Class 4

These diagrams indicate the variation across the class in terms of the numbers of friends in online and offline friendship groups, with some children having no or few online friends and others having many. From an analysis of the data collected from all 145 children, the following patterns emerged:

- 68 per cent of children had online friends in their class.

- Children who had only offline friends and children who had both online and offline friends had an average of nine offline friends each.

- Older children were more likely than younger children to play online with children they did not play with offline.

- Boys who played online had twice as many girls as friends (average 4.6) as boys who only played offline (average 2.3 ).

- Girls who played online had almost twice as many boys as friends (average 7.1) as girls who only played offline (3.6).

The greater propensity to play online with children of the opposite gender is of interest, given the way in which gendered patterns are often entrenched in children's offline social relationships (Renold, 2005; Thorne, 1993). It is also of note that children played online with their classmates, which resonates with data from older groups that suggests that online and offline friendships overlap (Subrahmanyam, Smahel and Greenfield, 2006) and that online use thickens existing social ties (Davies, 2008; Ito et al, 2009).

\section{(c) Copyrighted Material}




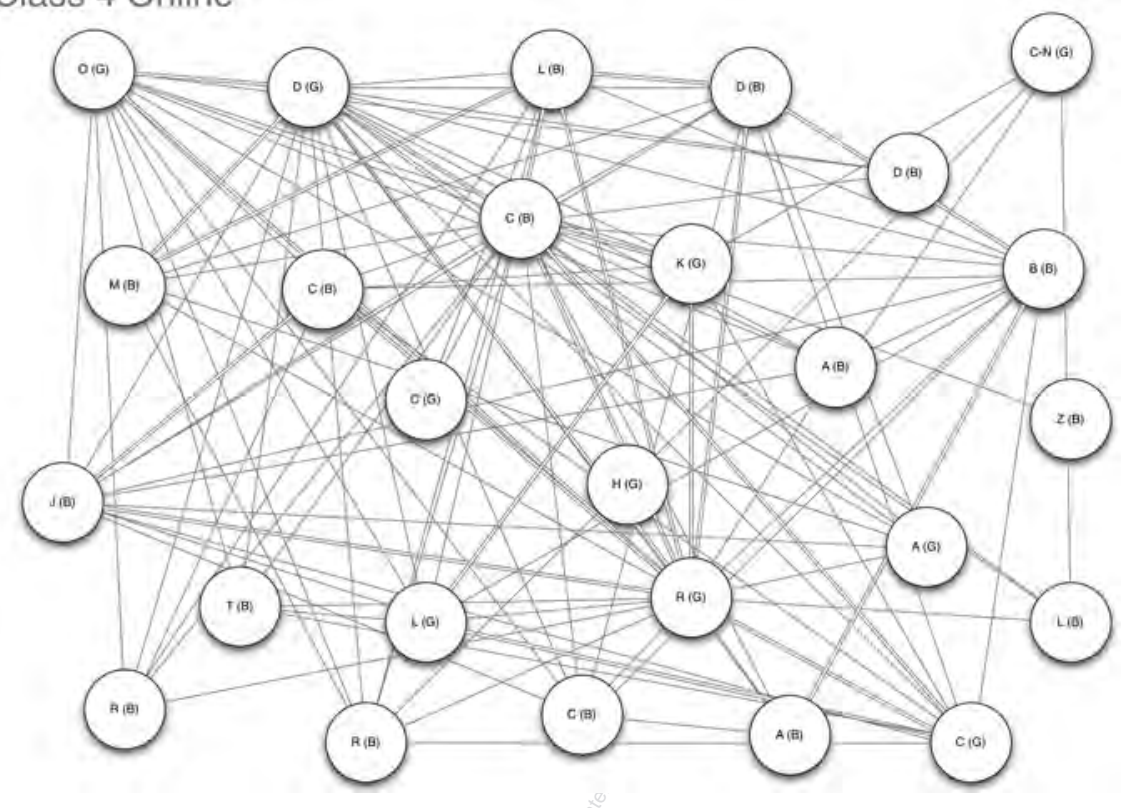

Fig. 5.3 Online friendships in Class 4

Following the completion and analysis of the sociographs, I interviewed 12 children across the three year groups in Key Stage 2 (Year Three, seven- and eightyear-olds; Year Four, eight- and nine-year-olds and Year Six, 10- and 11-yearolds) in order to explore potential issues of social exclusion due to lack of online activity. I wanted to identify how far children who did not participate in online activities felt excluded from offline activities. I did not interview children in Key Stage 1 due to the sensitivity of questions about social exclusion. I stressed to children in Key Stage 2 that they could refuse to answer questions and could stop the interview whenever they wished to do so. I identified a girl and a boy in each of the year groups Three to Six who, according to the sociographs had few (three or fewer) or no online friends, and girl and a boy in each of these year groups who had reported having lots of online friends (10 or more). I asked them about their online and offline friendships, who they played with, how they made their friendship choices and whether or not they felt the children who did not play online felt excluded from offline play in the playground. The interviews took place in the academic year following the completion of the sociographs, due to the summer holiday. Children were therefore asked to reflect on their friendships of the previous academic year, which may mean that their recollections were hazier than if they had been interviewed prior to the summer vacation.

In examining children's online friendships, it is worth noting that online behaviour in terms of befriending and de-friending is fraught with tensions, tensions which were not particularly evident in the interviews with this group 
of children. It would be useful to trace children's developing sense of the issues prevalent in managing online relationships over time in order to identify how and when particular patterns emerge. For the children at Monteney, means of managing their online relationships appeared to be implicit in nature, based on intuition, and drew from their offline experiences. Holmes (2011) suggests that the complexity of navigating online friendships requires an 'emotionalisation of reflexivity' and it could be argued that the children in this study were in the early stages of developing the capacity to engage in this process.

The six children who had few or no online friends did not, in the main, appear to be affected. Tom (Year Four) and Casey (Year Six), for example, reported that they were not aware that their peers were playing online with each other and therefore were, seemingly, unaffected by this. Similarly, John in Year Three was not aware that his friends were playing together online when he was in Year Two. John's father would not let him play on the Internet because of his fear that John would be the object of predatory behaviour by adults. However, this had now changed as John progressed to Year Three and he had been allowed online. I asked John if his dad let him play online with his friends:

John No.

Jackie Did you ever ask him?

John Yeah, but he said still no. When I asked him over and over he said, "No, no, no".

Jackie And did you feel upset or sad about that?

John No, I didn't thought I was missing 'owt [anything].

John then went on to mention a game he felt he was missing out on playing, however, a game which was undertaken in the playground:

John Well one game I missed out is playing dogs when I was in Y2 and in Y1.

Jackie You missed out playing ...?

John Dogs.

Jackie Dogs? Why did you miss out on that?

John 'Cos people say it's ... people don't play with me any more if I play

dogs.

Jackie Oh right. They didn't want you to play? Why do you think that was?

John Because I played dogs. 
It would seem that in this case, a feeling of exclusion came about not because of lack of opportunities to engage in online play, but because John wanted to play a game that others did not wish to play in the playground. Such face-to-face interactions, significant in matters of social exclusion, might suggest that recent concerns about the negative consequences of online activity for intimacy and trust in offline relationships (Turkle, 2011) can be given undue emphasis.

Lara, in Year Six, was aware that her friends were playing online, but she made a conscious decision that she did not want to play online very often and this did not impact upon her sense of being included in offline contexts:

Lara I knew that other children were on it, it's just like I didn't like want to get all fussy and everything because I don't go on it that much.

Jackie Yeah, what do you mean, "You didn't want to get fussy", what does that mean?

Lara Like I didn't want to go through all the trouble to not go on it so much, like.

Jackie Now explain to me. So if you made friends you'd have to go on it not as much?

Lara Well if I made like a lot of friends, a lot a lot of friends then I'd go on it a bit more, but I didn't really go on it so I only had that one friend.

Jackie And did you ever feel left out of any games because you didn't go online or make online friends?

Lara No.

Lara expresses a reluctance to become engaged in spending extensive time developing online friendships, a phenomenon also identified with older users of the Internet, who have complained about 'communication overload' (Agosto and Abbas, 2010:7). There appeared to be both time and technological constraints in terms of developing online networks. Jay in Year Four had only three online friends and he suggested that this was down to the management of the process:

Jay I played with lots of people on the playground but I played with a couple on the Internet.

Jackie Yeah, why didn't you play with everybody on the Internet?

Jay Because I would have to get up like 28 tabs and I could fit three on my screen.

Only one child in this group of six stated that she felt negatively about not playing with online friends. Gilly, in Year Three, was not allowed to use her 
parents' computer, 'Because someone might send me a nasty horrible e-mail'. She said that this lack of opportunity to engage in online play with her friends made her feel 'lonely'. In this instance, Gilly was being presented with different adult agendas: the parental one emphasising risk and the researcher's agenda relating to the exploration of patterns in friendship and social exclusion.

In the interviews with the six children who had many online friends, there were similar comments made about the perceived lack of impact for children who did not have many online friends, and the way in which online activities did not really influence playground friendships. I looked at the sociograph developed by Kate, in Year Three, with her.

Jackie So if we look at James, you played with James in the playground and online didn't you?

Kate Yeah.

Jackie But with Tony, you only played with him in the playground and you didn't play with him online. So I'm interested in why some children you play with both in the playground and online, and other children only in the playground?

Kate Well it's simple for some reasoning, because some people haven't got a computer.

Jackie Do you know they've not got a computer?

Kate Yeah.

Jackie How do you know?

Kate Because I ask if they've like got a Club Penguin or something and they say, "I haven't got a computer".

Jackie Oh right, OK. So how do you find out which friends you're going to play online with?

Kate We just arrange it at school and say, say go on it when we get back from school like, Moshi Monsters and stuff ...

Jackie And do you think you were more friendly with children that you played with on the Internet, or it was just the same?

Kate It was just the same.

Jackie You didn’t notice?

Kate No, I didn't notice. 
Kate dismissed my seemingly naïve question about why she played with some children online and not others by pointing out the 'simple' fact that some children did not have access to the Internet. This did not impact on her friendship choices in the playground. Similarly, Carl (Year Three) did not feel that there was a negative impact of children not being able to play online and reported playing in the playground with children who had no online presence.

Children reported playing online with other children that they played with in the playground, but also other children in the school who were not regular playmates. They would then not seek to play with these children in the playground, as this interview with Mandy, in Year Six, indicates:

Mandy Well usually the people online I usually ... the people that are online I usually just play with them, and then if I go out and play in the yard I kind of just play with all my friends and people like if they're not playing with anyone else and then go and talk to them and see what's the matter.

Jackie So you don't seek out people that you play with online?

Mandy Erm ... no.

Jackie Does it make any difference do you think in the playground or play with Moshi Monsters "I'll play with her today" or do you not think about it or ...?

Mandy No I don't usually think about it, I just like go to school and see who's there and play with them.

Jackie And are there some people that you wouldn't play with online?

Mandy Erm ... probably just people who I haven't got as a friend on Moshi Monsters, or people who aren't on with ... online or stuff like that. But I usually talk to everyone that's on.

For some children, therefore, online and offline networks appear to be distinct in nature, and children are content to play online with peers and then not pursue those friendships in the playground. This pattern was more likely to occur in the older year groups, as the younger children played primarily online with people they knew offline. Carl (Year Three) reported how he made decisions about who to play with online based on their offline behaviour:

Jackie ... So when you choose children to play with online, what makes you choose them?

Carl Because they're nice friends and I think they would love to play with me lots of time.

Jackie And when you play with children in the playground what makes you choose them? 
Carl I like them people but if they're online I think they would say bad words and that means they would get banned from it.

Jackie Who is that, who would do that?

Carl Someone like James because he's naughty.

Jackie How can you tell he's going to be naughty online?

Carl Because if they're naughty online you have to do something like a tick to show you're going to be good on it, and if you break that your account's going to get banned from Moshi Monsters.

Jackie Oh right OK, so it actually could hurt you if you played with children who did break the rules?

Carl Yeah, "cos it would talk me into the [indistinguishable] and they would ban ... if I did it, it would ban my account as well.

Jackie So how do you think you can tell the children who might break the rules then?

Carl Because erm ... if like they shout out and they thump people in faces sometimes ...

Jackie In the playground?

Carl Yeah. And if they're going to say something like "I don't like you", and like Casey when I've gone to his house, my nan - nan lives next door to him and I go to her house every night, Casey swears when we go round to play football, and that's why I didn't ask him to my accounts.

Jackie Oh right OK, because he might get you into trouble.

Carl Yeah.

Jackie And get you banned.

Carl Yeah. Because if they're banned we can never add that account on to Moshi Monsters ever again.

Jackie Oh gosh. And did Casey ever ask to be your friend on the Internet?

Carl Mmm, about 5 times.

Jackie And what did you say to him?

Carl I said "sorry, I don't want to get banned from it".

Jackie And what did he say?

Copyright material: You are not permitted to transmit this file in any format or media; it may not be resold or reused without prior agreement with Ashgate Publishing and may not be placed on any publicly accessible or commercial servers. 
Carl "Please!" like that. And I said, "No because I don't want to get banned, I want to play nice with my friends".

Jackie And did that make him change his play with you in the playground or not?

Carl No he's still hurting people, and he's still swearing when we go round to play football.

Carl's concern not to get banned from a virtual world appeared to have shaped his decisions about who to accept as an online friend. Jay (Year Four), had few online friends, as indicated previously, and he also made judgments about who to play with based on his offline experiences:

Jackie Was there anybody else that you would say, "Oh no I wouldn't play with them online"? You don't need to say names but is there anybody that ...

Jay Yeah, because he gets too competitive.

Jackie Oh, really, one of your friends?

Jay Like, "Oh, I really want to win it".

Managing online friendships was, for these children, a matter of making judgments based on observable behaviour of their peers in the offline world. Reputation is an important concept in terms of managing online relationships (Taylor, 2006). Trust with others is developed through perceptions of their online reputations, and aligning oneself with Internet users who may create problems is avoided by some through the practice of engaging only with Internet users they have some long-standing knowledge of (Xu, Cao, Sellen, Hebrich and Graepel, 2011).

Children in the study arranged to meet each other online at specific times and shared online usernames so they could track each other down. There was no suggestion in the interviews that children were sharing online usernames in a quest to gain as many online friends as possible, a practice which has been noted with teenagers and adults. Holmes (2011) in a study of adults' use of Facebook, cites the case of an individual called Margaret, who stressed how she accepts all friend requests on Facebook. Holmes notes that:

Those overly free in friending may be accused of 'friend farming' (collecting friends to look good) (Hardey 2008: 132) and Margaret's strategy of accepting all friend requests may lead to being labelled as a Facebook 'whore' who has too many friends and is interested in self display (Holland and Harpin 2008:1 to 6 to 8$)$.

Whilst this description might dismay those of us who object to the use of vocabulary which deprecates women ('whore'), it points to the way in which online behaviour in terms of befriending and de-friending is fraught with tensions. 
Through the sharing of usernames and developing of peer networks online that were based on school networks, the children were constructing online friendships that, in the main, demonstrated homophily, exacerbated by the fact that the school served a primarily white, working class community. Emergent research in this area suggests that adolescents demonstrate greater homophily in their online social networks than adults (Mazur and Richards, 2011) and this phenomenon deserves further attention in relation to the online practices of children under the age of 11 . The findings from this study would suggest that for children at Monteney, online and offline social networks and practices overlapped in complex ways and shaped both their online play and their playground activities. In the next section, I explore the relationship between online and offline play.

\section{Online and Offline Play}

In a previous study of the use of virtual worlds by children in Monteney Primary School, I explored the relationship between online and offline play and identified that forms of offline play could be found online, such as fantasy play, socio-dramatic play and games with rules (Marsh, 2010). For example, in the third category here, games with rules, children reported importing games such as hide-and-seek and musical chairs into their play in the virtual worlds Club Penguin and Habbo Hotel. In the study reported in this book, there were numerous opportunities to identify how online practices informed offline play. Across both school playgrounds, there appeared to be three ways in which online play permeated offline activities, which I have categorized as: naming the game, playing the game and gaming the game. In this context, 'game' is a term used to refer to online play in specific sites which contain game elements, such as virtual worlds and MMOGs.

\section{Naming the Game}

In this category, instances of play occurred in the playgrounds in which children were playing a game that did not utilise the specific characters or narrative structures of an online game, but, nevertheless, the offline play was given the title of the online game:

Sarah-Louise Sometimes I play with my friend and we take turns being 'Club Penguin'.

Jackie What do you have to do when you're 'Club Penguin'?

Sarah-Louise When you're 'Club Penguin' someone ... when you're standing like a star, you have to try and pass 'em and they're going sideways they try and stop you passing 'em but you have to try and unpass 'em ... when you dodge "em you jump over a log and if you touch a bench you win and someone else is 'Club Penguin'. 
What Stacey describes is a tag game which has been badged with the Club Penguin label. Similarly, as reported in Burn (2013), a five-year-old boy from Monteney suggested that he and his friends sometimes refer to their game as Call of Duty, even though what they actually played was a generic shooting game. These can be seen as examples of what Bishop et al (2006) term onomastic allusion, when children refer to the names of favourite characters, television programmes, films and other elements of popular culture, but the source text/artefact is not drawn upon in an extended manner. Such practices may serve to signal children's ownership of the right sort of cultural capital in order to extend friendships.

\section{Playing the Game}

In this category, children reported, or were observed, playing games in the playground that they had played online. Burn (2013) discusses this in relation to computer games and outlines how children adopt both the ludic system of the game (the game-like elements, such as its rules for winning, its economic system) and the representational system:

This provides landscapes, imaginary worlds, characters, narrative possibilities, and the resources for a dramatised experience analogous to, though in certain ways structurally distinct from, the narratives and representational systems of novels, films and plays (which also, of course, both resemble and differ from each other). (Burn, 2013)

It may be the case that play under this category may not relate just to the online form, but also representations of that text in other media. For example, I observed a group of boys in Key Stage 1 in the Monteney playground involved in an extended play episode based on the 'Avatar' theme. I had assumed that this play was informed by the film of the same name, but it could also be the case that such play may have been influenced by the children's engagement with the narrative in other forms, such as books or computer games, given the transmedia intertexuality prevalent in children's cultural practices (Kinder, 1991). Such play provides an example of 'heterotopian games', as described by Burn in Chapter 1, in which themes and characters from the virtual online world can be transposed into offline imaginative play, which evokes the virtual realm of fantasy.

\section{Gaming the Game}

This category refers to the way in which children might take the ludic elements of online games and use them to inform the structure of an offline game. In Chapter 1 , Burn suggested that this structural borrowing, which can be viewed as 'ludic bricolage', can be seen in the example of a group of girls in the Christopher Hatton playground who introduced the ludic structures of computer games, with the various levels players have to go through, into a game played with hoops set onto the playground surface. 
Similarly, in the Monteney playground, I observed a group of children playing a game in which a boy (the protagonist) was situated across a table from three other children. He pushed the children's heads so that they sank down onto the table. One of the girls stated that they had been poisoned and then the group all ran to a different part of the playground as the protagonist chased them. On questioning the group, they informed me that they had been playing the game 'Hotel', which I later identified as the free online game Hotel Management. This is not a particularly complex game; it involves a hotel receptionist who hands out keys to residents who then collect goods, which earn them money. In the Monteney example, just as in the Christopher Hatton 'Hoops' game, the children demonstrated the way in which they merged elements of online games with the more standard fare of playground pretend play, for example being poisoned by a wicked protagonist. In these activities, children are demonstrating well-established patterns, of course. Bishop and Curtis (2006) and Willett (2013) all discuss the way in which children integrate their media use with more folkloric forms of play in a rich hybrid mix.

In many ways, as I have argued here and elsewhere (Marsh, 2010), there are numerous continuities in online and offline play. Nevertheless, there are key differences. Burn (2013) notes three differences in relation to children's play on computer games and their offline play. The first relates to the perceptual distinction between them - in online play, the screen separates the player from the representations of the play world. The second difference is that in online play, children can control the avatar as a puppet, whereas in offline play, there is not such a direct relationship between intent and outcome. Third, the embodied experience is obviously different, as in online play, the avatar is bodily remote from the player, whereas in the playground, the player embodies the action. To this list, I would add three further differences, which relate to the previous discussion on friendships in online and offline spaces. First, in online play, the player is able to control the friendship group in ways which are not possible in the playground. If one does not wish to play with an avatar online, one can block them immediately and they no longer appear in the player's friendship list. This is not so easy in the playground, as children may resist attempts to reject them from a particular game, or linger at the edges once excluded to watch what is happening, which may irritate the other players. Second, judgments made about whom to play with offline are informed by knowledge of children's offline identity and practices. Whilst this knowledge does inform choices with regard to online friendships, as in the case of Carl (discussed previously in this chapter), it cannot always be the case. In these instances, children use other ways to judge whether or not they wish to play with another online user, which includes, at times, idiosyncratic judgments about the names and appearances of avatars and virtual homes (Marsh, 2012; 2013). Finally, in online play, the social relationships which often shape the nature and direction of play in offline contexts are not as discernible or able to influence play in the same way as they do in offline contexts and this can lead to children wanting to create opportunities online to thicken social friendships through ritualised play practices (Marsh, 2011).

\section{C) Copyrighted Material}

Copyright material: You are not permitted to transmit this file in any format or media; it may not be resold or reused without prior agreement with Ashgate Publishing and may not be placed on any publicly accessible or commercial servers. 


\section{Conclusion}

From the data discussed in this chapter, it would appear that children at Monteney Primary School identified few negative consequences of not engaging in online play with their classmates. Only one child suggested that she felt excluded and the others stated either that there was no social exclusion due to this reason, or that they had not noticed any social exclusion. Children made decisions about who to play with online on the basis of their offline behaviour and generally tended to play with children online that they knew offline, that is, primarily their classmates. There appeared to be distinctions made about online and offline play, in that the children did not necessarily wish to play offline with children with whom they played online. Online social networks were more diverse than offline social networks, in that some children played online with children they did not play with in the playground and some were more likely to play with children of a different gender than themselves in an online context.

The offline and online continuum was also evident in relation to the distribution of play narratives across space and time. Children discussed playing, for example, Club Penguin as an online virtual world, as a Nintendo DS game on a console player, as a card collection practice and as a playground game of 'tag'. They purchased Club Penguin merchandise in local shops and the Disney store in an out-of-town shopping mall and some of these purchases enabled children to unlock online coins in the virtual world. This complex mix of practices effectively merged online and offline play spaces and contributed to their experience of play as a narrative-driven 'semiotic system' (Fleming, 1996).

There are numerous implications for the ongoing study of children at play. It is clear that contemporary playgrounds are shaped by children's engagement in online practices outside of school in a variety of ways and that the boundary between the online and offline is becoming more diffuse as technological developments continue to accelerate and shape the play environment. Whilst accepting Boellstorff's (2008) assertion that there are clear ontological differences between online and offline activities, I would wish to argue that there are also numerous similarities in terms of children's play. Not only are forms of play consistent across online and offline spaces (Marsh, 2010), but children talk about and engage in play in the playground which draws from their online experiences, as outlined in this chapter. Although of course it is valuable to examine children's play in specific domains, in future years it would be of interest to trace the movement of play and the circulation of discourses across online and offline spaces. In particular, there are questions raised by this study that deserve further attention. Although children's voices have been present throughout the chapter in the form of excerpts from interview transcripts, what is offered in summary are etic rather than emic perspectives; it may be the case that there are differences and tensions between children's views of online/ offline continuities and discontinuities and those of the adult researchers involved in the study. Nevertheless, I would suggest that both emic and etic viewpoints are of value and can offer different perspectives on the same phenomena (Martin, 2002:38). In addition, there are questions concerning the ways children do and 
can respond to the need for the 'emotionalisation of reflexivity' (Holmes, 2010) in managing friendships in online spaces. How can children who fail to develop trust in their offline relationships manage their entry into online networks? What happens when children who do not engage with particular online texts and spaces wish to participate in offline play which draws on these texts and practices? In what ways do narratives of play change across online and offline domains? These are questions that need to be explored by sociologists and anthropologists of childhood in the years ahead if we are to develop a more rounded understanding of play in the digital age.

\section{References}

Agosto D and Abba J (2010) High School Seniors' Social Network and Other ICT Use Preferences and Concerns. ASIST Conference, 22-27 October 2010, Pittsburgh, PA, USA. https://www.asis.org/asist2010/proceedings/ proceedings/ASIST_AM10/submissions/25_Final_Submission.pdf

Bishop JC and Curtis M with Woolley H, Armitage M and Ginsborg J (2006) Participation, popular culture and playgrounds: Children's uses of media elements in peer play at school. Paper presented at the Folklore Society Conference, Folklore, Film and Television: Convergences in Traditional Cultures and Popular Media, 31 March-1 April 2006, London.

Blanchard J and Moore T (2010) The Digital World of Young Children: Impact on Emergent Literacy. Pearson Foundation White Paper. Retrieved from: http// www.pearsonfoundation.org/PDF/EmergentLiteracy-WhitePaper.pdf

Boellstorff T (2008) Coming of Age in Second Life: An Anthropologist Explores the Virtually Human. Princeton: Princeton University Press.

Buckingham D (2011) The Material Child. Oxford: Polity.

Buckingham D (1993) Children Talking Television: The Making of Television Literacy. London: Falmer Press.

Burn A (2013) Computer games on the playground: ludic systems, dramatized narrative and virtual embodiment. In Willett R, Richards C, Marsh J, Burn A and Bishop JC. Children, Media and Playground Cultures: Ethnographic Studies of School Playtimes. Basingstoke: Palgrave Macmillan.

Cook D (2008) The missing child in consumption theory. Journal of Consumer Culture 8: 219-43.

Cook D (2010) Commercial enculturation: Moving beyond consumer socialization. In Buckingham D and Tingstad V (eds) Childhood and Consumer Culture. Basingstoke: Palgrave Macmillan.

Davies J (2008) Online connections, collaborations, chronicles and crossings. In Willett R, Robinson M and Marsh J (eds) Play, Creativities and Digital Cultures. New York: Routledge.

Dowdall C (2008) The texts of me and the texts of us: Improvisation and polished performance in social networking sites. In Willett R, Robinson M and Marsh J (eds) Play, Creativities and Digital Cultures. New York: Routledge.

Copyright material: You are not permitted to transmit this file in any format or media; it may not be resold or reused without prior agreement with Ashgate Publishing and may not be placed on any publicly accessible or commercial servers. 
Fleming D (1996) Powerplay: Toys as Popular Culture. Manchester: Manchester University Press.

Gilbert B (2009) Virtual Worlds Market Forecast 2009-2015. Strategyanalytics, Retrieved March 2010 from http://www.strategyanalytics.com/default.aspx?m od=ReportAbstractViewer\&a0 $=4779$

Hardey M (2008) Seriously social: making connections in the information age, Unpublished $\mathrm{PhD}$ Thesis, University of York.

Holland S and Harpin J (2008) "It's only MySpace": Teenagers and social networking online'. In Holland S (ed.) Remote Relationships in a Small World, New York: Peter Lang.

Holmes M (2011) Emotional reflexivity in contemporary friendships: Understanding it using Elias and Facebook etiquette. Sociological Research Online 16. <http://www.socresonline.org.uk/16/1/11.html> 10.5153/sro.2292

Ito M, Baumer S, Bittanti M, Boyd D, Cody R, Herr-Stephenson B, Horst H A and Tripp L (2009) Hanging Out, Messing Around and Geeking out: Kids Living and Learning with New Media. Cambridge, MA: The MIT Press.

Kafai YB, Fields DA and Cook MS (2010) Your second selves: Player-designed avatars. Games and Culture 5: 23-42.

Kinder M (1991) Playing with Power in Movies, Television, and Videogames: From Muppet Babies to Teenage Mutant Ninja Turtles. Berkeley: University of California Press.

Lauwaert M (2009) The Place of Play: Toys and Digital Cultures. Amsterdam: Amsterdam University Press.

Levin DE and Rosenquest B (2001) The increasing role of electronic toys in the lives of infants and toddlers: Should we be concerned? Contemporary Issues in Early Childhood 2: 242-7.

Livingstone S (2009) Children and the Internet. Cambridge: Polity.

Luke C (2000) What next? Toddler netizens, Playstation thumb, techno-literacies. Contemporary Issues in Early Childhood 1: 95-100.

Malpas J (2009) On the non-autonomy of the virtual. Convergence: The International Journal of Research into New Media Technologies 15: 135-9.

Marsh J (2013) Breaking the ice: Play, friendships and social identities in young children's use of virtual worlds. In Burke A and Marsh J (eds) Children's Virtual Play Worlds: Culture, Learning and Participation. New York: Peter Lang, 59-78.

Marsh J (2012) Countering chaos in Club Penguin: Young children's literacy practices in a virtual world. In Merchant G, Gillen J, Marsh J and Davies J (eds) Virtual Literacies: Interactive Spaces for Children and Young People. New York: Routledge.

Marsh J (2011) Young children's literacy practices in a virtual world: Establishing an online interaction order. Reading Research Quarterly 46: 101-18.

Marsh J (2010) Young children's play in online virtual worlds. Journal of Early Childhood Research, 8: 23-39.

Marsh J, Brooks G, Hughes J, Ritchie L and Roberts S (2005) Digital beginnings: Young children's use of popular culture, media and new technologies. 
Sheffield: University of Sheffield. Retrieved 18 July 2012, at http://www. digitalbeginings.shef.ac.uk/

Martin J (2002) Organizational Culture: Mapping the Terrain. London: Sage.

Mazur E and Richards L (2011) Adolescents' and emerging adults' social networking online: Homophily or diversity? Journal of Applied Developmental Psychology 32: 180-88.

McLaughlin M, Osbourne K and Smith C (1995) Standards of conduct on Usenet. In Jones S (ed.) Cybersociety: Computer-mediated Communication and Community. London: Sage.

Meyers E (2009) Tip of the iceberg: meaning, identity, and literacy in preteen virtual worlds. Paper presented at 2009 ALISE Conference. Retrieved 8 January 2010 from http://blogs.iis.syr.edu/alise/archives/71

Meyers EM, Nathan LP and Unsworth K (2010) Who's watching your kids? Safety and surveillance in virtual worlds for children. Journal of Virtual Worlds Research 3: 3-28.

Miller P and Rose N (1997) Mobilising the consumer: assembling the subject of consumption, Theory, Culture and Society 14: 1-36.

Nardi B (2010) My Life as a Night Elf Priest: An Anthropological Account of 'World of Warcraft'. Ann Arbor, MI: University of Michigan Press.

Ofcom (2011) Children and parents: media use and attitudes report. October 2011. http://stakeholders.ofcom.org.uk/binaries/research/media-literacy/oct2011/ Children_and_parents.pdf

Opie I and Opie P (1988) The Singing Game. Oxford: Oxford University Press.

Palmer S (2006) Toxic Childhood. London: Orion Press.

Pugh AJ (2009) Longing and Belonging: Parents, Children and Consumer Culture. Berkeley: University of California Press.

Putnam G (1997) Dissociation in Children and Adolescents: A Developmental Perspective. New York: Guilford Press.

Rapoport A and Horvath WJ (1961) A study of a large sociogram. Behavioural Science 6: 279-91.

Renold E (2005) Girls, Boys and Junior Sexualities: Exploring Childrens' Gender and Sexual Relations in the Primary School. London: Routledge/Falmer.

Robinson V (2007) The cyberself: The self-ing project goes online, symbolic interaction in the digital age. New Media \& Society 9: 93-110.

Shade LR and Grimes S (2005) Neopian economics of play: Children's cyberpets and online communities as immersive advertising in NeoPets.com. International Journal of Media and Cultural Politics 1: 181-98.

Shariff S (2008) Cyber Bullying: Issues and Solutions for the School, the Classroom and the Home. New York: Routledge.

Subrahmanyam K, Smahel D and Greenfield P (2006) Connecting developmental constructions to the Internet: Identity presentation and sexual exploration in online teen chatrooms. Developmental Psychology 42: 395-406.

Taylor TL (2006) Play Between Worlds: Exploring Online Game Culture. Cambridge, Mass: MIT Press.

\section{(c) Copyrighted Material}

Copyright material: You are not permitted to transmit this file in any format or media; it may not be resold or reused without prior agreement with Ashgate Publishing and may not be placed on any publicly accessible or commercial servers. 
Thomas A (2007) Youth Online: Identity and Literacy in the Digital Age. New York: Peter Lang.

Thorne B (1993) Gender Play: Girls and Boys in School. New Brunswick: Rutgers University Press.

Turkle S (2011) Alone Together. Cambridge, Mass: MIT Press.

Valentine G and Holloway S (2002) Cyberkids? Exploring children's identities and social networks in on-line and offline worlds. Annals of the Association of American Geographers 92: 302-19.

Warner M (2009) Out of an old toy chest. Journal of Aesthetic Education 43: 1-16.

Willett R (2013) Superheroes, naughty mums and witches: Pretend family play amongst seven to ten year-olds. In Willett R, Richards C, Marsh J, Burn A and Bishop, JC. Children, Media and Playground Cultures: Ethnographic Studies of School Playtimes. Basingstoke: Palgrave Macmillan.

Xu Y, Cao X, Sellen A, Herbrich R and Graepel T (2011) Sociable Killers: Understanding Social Relationships in an Online First-Person Shooter Game. Proceedings of the ACM Conference on Computer supported cooperative work, New York, 2011. http://research.microsoft.com/en-us/people/xiangc/ cscw2011_sociablekillers.pdf 
Copyright material: You are not permitted to transmit this file in any format or media; it may not be resold or reused without prior agreement with Ashgate Publishing and may not be placed on any publicly accessible or commercial servers. 